\title{
Impulso Social y Empresarial en Época de Pandemia
}

\section{Social and Business Boost in Time of Pandemic}

Roberto Xavier MANCIATI-ALARCÓN ${ }^{1}$ (iD

1. Universidad UTE, Facultad de Ciencias Administrativas, Ecuador.

Email: roberto.manciati@ute.edu.ec

\section{Resumen}

El desarrollo de la pandemia causada por el covid-19 a nivel global durante los últimos dos años ha obligado a introducir nuevos enfoques en el manejo de los procesos organizacionales, lo cual ha transformado empresas, gobiernos e incluso la vida cotidiana, con consecuencias sin precedentes en el Ecuador y el mundo entero.

En el ámbito laboral se presentó una crisis de sostenibilidad, donde muchas empresas optaron por reducir el número de empleados o por disminuir la carga en horas de trabajo, con la consecuente reducción salarial. Si bien estos cambios suponen la oportunidad de nuevas opciones laborales, productivas y comerciales, también surgen necesidades apremiantes producto de las reestructuraciones de cada sistema empresarial.

\section{Palabras clave}

Pandemia covid-19, sostenibilidad laboral, restructuración empresarial.

\section{Abstract}

The development of the covid-19 pandemic at a global level during the last two years has introduced new approaches in the management of organizational processes, managing to transform companies, governments and even daily life, with unprecedented consequences in Ecuador and the entire world.

In the workplace there is a sustainability crisis, where many companies opted to reduce the number of employees, reducing the load in working hours with its consequent salary reduction, opening the doors to new employment, productive and commercial options, and emerging pressing needs based on restructuring of each business system.

\section{Keywords}

Covid-19 pandemic, labor sustainability, business restructuring. 


\section{Introducción}

La presencia de la covid-19 en la sociedad del siglo XXI ha influido en el establecimiento de varios paradigmas orientados al manejo de los procesos organizacionales, causados principalmente por la revolución digital que ha transformado sociedades, sistemas, empresas, economías, gobiernos e incluso la forma de enfrentar diariamente la vida dentro y fuera del hogar, lo cual ha generado consecuencias sin precedentes en los países de la región y el mundo entero. En el ámbito laboral, los resultados de los últimos 24 meses muestran amplias crisis de sostenibilidad y estabilidad, puesto que muchas empresas, amparadas en las normativas legales producto de la emergencia sanitaria, optaron por reducir el número de empleados o por disminuir la carga en horas de trabajo con la consecuente reducción salarial.

Este nuevo orden mundial en el manejo de conflictos, pandemias, procesos políticos y empresariales ha abierto las puertas a nuevas opciones laborales, productivas y comerciales. Asimismo, la virtualidad se ha convertido en un sistema de amplio uso en instituciones educativas, sistemas empresariales, procesos financieros, entre otros, que desafía a los procesos tradicionales implantados décadas atrás que, al encontrarse enraizados en la sociedad, se convertían en el punto de partida para cualquier actividad humana. Actualmente, los sistemas empresariales y las plataformas comunicacionales se han visto obligadas a innovar en respuesta a una inusitada competencia tecnológica que al tiempo busca soluciones a esquemas caducos e incompletos en cuanto al manejo de las relaciones e información.

La acelerada digitalización en beneficio de la información se consolida logrando una múltiple direccionalidad en formatos de comunicación entre empresarios, vendedores, clientes y socios; de ahí que la permanente evolución de los grupos de interés muestre apremiantes necesidades con base en restructuraciones de cada sistema empresarial.

\section{La crisis de sostenibilidad y la reestructuración empresarial}

Al igual que el resto de países, el Ecuador se mantiene a la expectativa de los avances y afectaciones de la covid-19. La enfermedad fue detectada el 17 de noviembre de 2019. El 30 de enero de 2020, la Organización Mundial de la Salud (2020, enero 30) la declaró emergencia de salud pública de preocupación internacional. Por este motivo, el Gobierno de Lenín Moreno, mediante el Acuerdo Ministerial N. ${ }^{\circ}$ 00126-2020, emitido el 11 de marzo de 2020 por la ministra de Salud, declaró el Estado de Emergencia Sanitaria en el Sistema Nacional de Salud, y el 13 de marzo de 2020, el Gobierno ordenó que se active el Centro de Operaciones de Emergencias (COE) Nacional para la coordinación de la emergencia. Finalmente, en respuesta a las afectaciones a nivel nacional, el 23 de marzo de 2020 se formalizó el estado de excepción (Constitución de la República del Ecuador, 2008).

Luego de estas acciones en defensa y cuidado de la salud, tanto de los ecuatorianos como de los extranjeros que visitaban nuestro país, se iniciaron las campañas de salud que fueron difundidas por todos los medios de comunicación del Ecuador. Con la difusión se logró, en cierta medida, concientizar a la población sobre el cuidado y la protección de su vida, por medio del uso de la mascarilla y el alcohol antiséptico, además del distanciamiento social, la prohibición de asistir a eventos públicos, el cierre de lugares que propenden a la aglomeración social y otras medidas para precautelar la salud y vida de la ciudadanía (Martin-Fiorino \& Reyes, 2020).

Han pasado 24 meses del inicio de esta lamentable pandemia y, al momento, las ci- 
fras oficiales que el Ministerio de Salud Pública (2021, octubre 26) maneja son las siguientes:

- 515632 casos confirmados con pruebas PCR (reacción en cadena de la polimerasa)

- 48442 casos con alta hospitalaria

- 32952 fallecidos por covid-19

- 1540122 muestras para RT-PCR

- 423688 recuperados

- 1296915 casos descartados

- 21448256 vacunas administradas

- 11708111 personas vacunadas

- 10032731 personas completamente vacunadas (2 dosis)

Esto da la medida de que a pesar de los duros momentos de meses atrás, la decisión política del actual régimen ha puesto la energía necesaria para subsanar este grave problema.

A partir de las cifras expuestas, existe la necesidad de que en el sector empresarial se activen, con visión de futuro, los procesos laborales, comerciales y productivos que, al haber enfrentado gran cantidad de problemas producto de la crisis sanitaria, se han visto obligados a replantear la iniciativa emprendedora a fin de subsanar cada una de las secuelas que se produjeron en el ámbito empresarial. Esto se refleja en

que las preocupaciones y necesidades del $83 \%$ se concentraron hacia los clientes, la continuidad de atención, retención de clientes y todo lo relacionado a ventas, seguido por el $74 \%$ relacionado con temas financieros como la liquidez, la planeación financiera, la provisión de pagos, seguimiento a CxC, préstamos bancarios, entre otros. (AndeanEcuador \& Deloitte, 2020, agosto, p. 3; Deloitte, 2020)

La situación financiera y comercial en todo formato empresarial se vio forzada, en cierto momento, a generar un inusitado replanteamiento de mercado, enfocado en la premisa de "emprendimientos vs. covid". Dicho de otra manera, un enfrentamiento de esquemas de vida de subsistencia y de existencia. Es difícil comprender que en un siglo en el que la tecnología ha adquirido tanta relevancia para el desarrollo y el conocimiento humano, nos veamos arrinconados a permanecer bajo estrictas disposiciones de distanciamiento social; más aún cuando

el $84 \%$ de las empresas ha disminuido sus ventas, de estas un $29 \%$ considera que las ventas disminuyeron entre $10 \%$ al $25 \%$, y el $24 \%$ considera que la reducción fue del $25 \%$ al $50 \%$. (Deloitte, 2020)

Pese a la pujante energía de los emprendedores ecuatorianos, el ministro de Producción y Comercio Exterior, Julio Prado, declaró que, al 07 de julio del 2021, más de 22000 empresas desaparecieron en el país como consecuencia de los efectos de la pandemia y los períodos de restricciones aplicados (Agencia EFE, 2021, julio 7). Asimismo, al 17 de octubre de 2021, se conoció que alrededor de 4.9 millones de personas fallecieron a nivel mundial a consecuencia de la covid-19 (Orús, 2021). Este panorama cambió radicalmente los esquemas de preferencias en consumo, compras, actividades, formatos laborales, relaciones humanas, entre otros. Actualmente, la consolidación de esquemas de trabajo virtual brindan opciones para renovar y/o replantear los sistemas laborales en innovadores paradigmas empresariales, los cuales han impulsado a las nuevas generaciones de profesionales a fortalecer las capacidades de talento social en emprendimientos y consolidación de proyectos productivos y comerciales.

De igual forma, el sector empresarial se ha visto obligado a desarrollar iniciativas que le permitan mantener la preferencia de consumidores en el mercado. Esta obligación es mayor cuando la competencia, impulsada por esquemas de comercialización virtual, muestra que el consumidor puede demandar menor tiempo en escoger nuevas marcas y productos que con seguridad podrían inte- 
riorizarse como líderes en la preferencia del gran mercado de consumidores en el país, y por qué no decirlo, del mundo entero.

Aparte, las empresas emergentes o startups se han convertido en tan corto tiempo en emprendimientos de corta generación o edad temprana que aplican las opciones o requerimientos del momento con grandiosas posibilidades de crecimiento. Esto se debe a que comercializan productos y servicios sin la existencia de fronteras entre países y utilizando tecnologías de información, lo que convierte a estos emprendimientos en exitosos modelos de innovación y diseño, marketing, crecimiento, comercio electrónico y rutas de mercado, que logran generar el impacto que el sector empresarial no había tomado en cuenta como una opción válida para su crecimiento, reinvención y opciones financieras de abaratar costos en procesos tradicionales de comercialización directa con el consumidor final (Stiglitz \& Greenwald, 2019).

La generación de un nuevo canal digital de ventas ha permitido que varios proyectos - que hasta finales de 2019 eran sueños imposibles de alcanzar por la desconfianza o por no tener una aplicabilidad aparente para los consumidores - se hayan convertido en una gran oportunidad comercial para productores, proveedores de materia prima, mano de obra calificada, distribución y entrega de productos, plataformas digitales de cobranza, pagos y transferencias, y principalmente, que surja un nuevo mundo de crecimiento empresarial que, a partir de la iniciativa de empresarios y jóvenes profesionales, pueda revolucionar el espectro comercial en los cinco continentes (Organización Internacional del Trabajo, 2021).

Frente al desafío de superar las limitantes de mercado impuestas por la presencia de la covid-19, Phil O'Reilly, presidente del Comité Consultivo Empresarial de la Organización para la Cooperación y el Desarrollo
Económicos (OECD, 2020, p. 12) plantea: “las organizaciones empresariales han tenido que lidiar con cuestiones absolutamente inéditas; han tenido que articular y construir nuevas capacidades rápidamente". De ahí la valoración que el mercado plantea en reconocimiento a los proyectos empresariales que, de una u otra manera, han logrado enfrentar la crisis actual con base en los procesos de apoyo práctico a las empresas; generar la unidad empresarial a fin de alcanzar sustentos recíprocos entre sectores vinculados por sus líneas de producción y (o) de comercialización; motivar acciones tendientes a fortalecer liderazgos intelectuales en beneficio de impulsar iniciativas que fortalezcan proyectos empresariales, $y$, finalmente, crear los proyectos corporativos para recibir contribución de partes interesadas en el desarrollo y crecimiento institucional. En esta última parte deberá tomarse en cuenta al Gobierno nacional porque mientras mejores números tengan las empresas privadas, mejores niveles de impuestos serán recuperados y más altos porcentajes de empleo podrán ofertarse en el país.

La difícil situación enfrentada por el sector empresarial ocasionó una considerable disminución en ventas, lo que causó dificultades financieras. No obstante, y al contrario de lo que se pensaba al inicio de la pandemia, el sector empresarial se ha fortalecido de manera sorprendente, debido a la necesidad de reencontrarse con la competencia, a las obligaciones financieras adquiridas antes de la pandemia, a los ineludibles compromisos económicos que mensualmente debe cumplir $y$, de manera esencial, a esa energía interior de desafiar las adversidades. A partir de estas puntualizaciones, nacen inquietudes que obligan a dar respuestas sin derecho a equivocación: ¿Cuáles son las empresas que han tenido más éxito durante la pandemia? ¿A qué sectores de la economía pertenecen?, ¿Por qué 
han logrado el éxito?, ¿Qué hicieron distinto al resto de las empresas? ¿Está mi empresa en ese grupo?, ¿He asumido con madurez y visión empresarial cada una de las decisiones tomadas?, ¿He logrado aplicar procesos innovadores en la producción, promoción y comercialización de mis productos?, ¿He logrado identificar nichos de mercado y segmentos específicos para consolidar la presencia de mis productos y/o servicios en el mercado?, entre otras.

Está claro que el sector empresarial ecuatoriano se encuentra frente a un escenario inédito de sostenimiento financiero, de ahí la incertidumbre y el compromiso empresarial de fortalecer cada proceso que consolide los cambios aplicados en los esquemas y diagramas empresariales. Es necesario impulsar ahora una consulta empresarial sobre los retos para el desarrollo empresarial en la pospandemia.

Al respecto, se presenta como el más evidente reto cumplido la acelerada transformación digital en cada proceso de la empresa, incluso en la cotidianidad de la vida humana, que con una excepcional rapidez logró fortalecer procesos y preparar a todos los niveles empresariales a una transformación digital que se creía tan lejana y que abrió las puertas para establecer esquemas de adquisición de equipamiento tecnológico, logrando así la aplicación de modelos de negocios innovadores y procesos de capacitación en competencias digitales. Además, es el momento oportuno para incluir el análisis de nuevas modalidades de emprendimientos con entregas a domicilio, cursos virtuales para capacitación, incremento de las ventas de computadores, mayor demanda de paquetes de internet y más iniciativas desde los elementales preceptos del emprendimiento, posibilitando la generación de recursos económicos para subsistir en épocas que la economía del país se encuentra debilitada.
Es necesario destacar que no todos los empleos que se perdieron producto de la pandemia podrán ser recuperados en el corto plazo, pues muchas de las empresas que los ofertaban han cambiado e innovado las modalidades laborales a esquemas basados en la nueva tendencia virtual de la economía laboral. Este escenario impulsa el arranque para crear emprendimientos que generen recursos económicos en otras áreas del negocio, aprovechando oportunidades que produzcan un alto potencial de crecimiento que en el futuro próximo permitirá la apertura de una mayor demanda laboral en el país (Rivas, 2021, febrero 14).

En suma, la sociedad ecuatoriana y especialmente los jóvenes profesionales deberán enfrentar desafíos que permitan crear oportunidades de generar ingresos económicos basados en una clara reconfiguración del esquema tradicional de "buscar empleo", y transformarlas en la opción de elaborar propuestas de emprendimiento que no solo fortalezcan su economía, sino también la de la localidad, la de la región y la del país. Queda claro que el cambio generacional en los esquemas laborales por procesos digitales ha abierto muchas puertas en el exitoso proceso digital del comercio y el negocio.

\section{Consideraciones finales}

Producto de un absoluto desentendimiento del desarrollo económico, comercial y empresarial, nuestro país se ha visto enfrentado por muchas décadas a regímenes gubernamentales que han buscado todas las formas posibles de generar ingresos por medio de iniciativas impositivas que denotan las diferencias de desarrollo y apoyo empresarial en comparación con Colombia, Perú y otros países de la región. Llegando incluso durante estas crisis económicas a generarse fenómenos migratorios hacia otros países en vista de que las familias con bajos ingresos no han sido capaces de sustentar adecuadamente 
la solvencia económica que en parámetros de dignidad social afectan su impulso.

Es oportuno destacar que al 25 de octubre de 2021 se publicó de manera oficial que en mayo de este año tan solo el $30.2 \%$ de la población tenía un empleo adecuado. Actualmente, esta cifra ha subido al $33.5 \%$, según la última encuesta nacional de empleo, desempleo y subempleo (Instituto Nacional de Estadísticas y Censos, 2020, agosto 2; 2021, octubre 25). Estos datos, a más de motivar las opciones de generar empresas, muestran un incremento del empleo adecuado, según datos oficiales. Sin embargo, los datos publicados por el Gobierno nacional que aparentemente generarían tranquilidad social, en el campo laboral y económico, son difíciles de comprender, puesto que no se respira ese aire de recuperación en los niveles sociales, laborales y de las microempresas.

\section{Referencias}

Agencia EFE. (2021, julio 7). Más de 22000 empresas desaparecieron en Ecuador durante la pandemia. https://bit.ly/3pZtd11

AndeanEcuador \& Deloitte. (2020, agosto). Encuesta situación empresarial: Ecuador. Deloitte. https://bit.ly/31g3KGR

Constitución de la República del Ecuador. (2008). Registro Oficial 449, 20 de octubre.

Deloitte. (2020). Elimpacto económico del covid-19: Nuevo coronavirus. https://bit.ly/3w5vARy

Instituto Nacional de Estadística y Censos (2020, agosto 2). Encuesta de empleo, desem- pleo y subempleo-ENEMDU. https://bit. ly/3bwo1db

Instituto Nacional de Estadística y Censos (2021, octubre 25). Reporte de mercado laboral. https://bit.ly/3ByJs7V

Martin-Fiorino, V., \& Reyes, G. (2020). Desafíos y nuevos escenarios gerenciales como parte de la herencia del covid-19. Revista Venezolana de Gerencia, 25(90), 71-722. https://bit.ly/3c4kEKN

Ministerio de Salud Pública. (2021, octubre 26). Situación epidemiológica nacional covid-19, Ecuador. https://bit.ly/3my1p2e

Organización Internacional del Trabajo. (2021). Liderazgo empresarial durante la crisis de la covid-19: Análisis de las actividades de las organizaciones empresariales durante la pandemia de covid-19 y siguientes pasos. https://bit.ly/3w6yC83

Organización Mundial de la Salud. (2020, enero 30). Coronavirus disease (covid-19). https://bit.ly/3bxvfh8

Organización para la Cooperación y el Desarrollo Económicos (OECD). (2020). Impacto social del covid-19 en Ecuador: Desafíos y respuestas. Making Development Happen. https://bit.ly/2ZMvrqo

Orús, A. (2021, noviembre 11). Covid-19: Número de muertes a nivel mundial por continente en 2021. Statista. https://bit.ly/3pY6iEa

Rivas, G. (2021, febrero 14). Innovación y desarrollo productivo en la era del covid-19: Lecciones de 2020; desafíos de 2021. Puntos sobre la i: Ciencia Tecnología e Innovación (BID). https://bit.ly/3EznEuN

Stiglitz, J., \& Greenwald, B. (2019). La creación de una sociedad del aprendizaje (2. ${ }^{\text {a Ed}) . ~ P l a n e t a . ~}$ 